\section{Single-tree influence on understorey vegetation in five Chinese subtropical forests}

\author{
Hai-Ying Liu ${ }^{(1)}$, Rune Halvorsen ${ }^{(2)}$
}

The aim of this study is to examine the effect of individual canopy tree on the species composition and abundance of understorey vegetation in subtropical forests, by applying a model for tree influence on understorey vegetation of boreal spruce forests developed by Økland et al. (1999), according to the principles of Ecological Field Theory (EFT). The study was based upon five vegetation data sets, each with two subsets (vascular plants species and bryophytes species) from subtropical forests in south and southwest China. Optimal value of tree influence model parameters was found by maximizing the eigenvalue of a Constrained Ordination (CO) axis, obtained by use of the EFT-based tree influence index as the only constraining variable. One $\mathrm{CO}$ method, Redundancy Analysis (RDA), was applied to five vegetation data sets. The results showed that the optimal EFT tree influence models generally accounted for only a small part of the variation in species composition (the eigenvalues of RDA axes were low, amounted to $1-10 \%$ of total inertia). The higher eigenvalue-tototal-inertia ratio with RDA was interpreted as due mainly to the low species turnover along the tree influence gradient. Vascular plants and bryophytes species differed with respect to optimal parameters in the tree influence model, especially in a conifer dominated forest. Compositional turnover associated with tree influence indices was also generally low, although somewhat varies among study areas. Thus, it was concluded that single-tree EFT models may have limited suitability for studied subtropical forests; different optimal parameters in the tree influence model obtained for vascular plants and bryophytes species in two studied areas indicates that subtropical trees may impact vascular plants and bryophytes species in different ways; and trees may influence the understorey species composition more in a collective manner than through the influence of single individuals in studied subtropical forests.

Keywords: Competition, Understorey Vegetation, Bryophytes, Vascular Plants, Ecological Field Theory, Individual Tree Models

\section{Introduction}

Canopy trees may influence understorey species composition in an individual or collective manner (Økland \& Eilertsen 1993, Kuuluvainen 1994, Økland et al. 1999, Berger \& Puettmann 2000, Michalet et al. 2002, Barbier et al. 2008, Chávez \& Macdonald 2010, Strong 2011). In boreal forests, the properties of tree layer have proven important as determinants of understorey properties such as micro-climate, soil moisture, litter depth, litter distribution and light conditions (Økland 1996). The distance from a given point on the forest floor to the nearest trees and the properties of these trees were important predictors of understorey species composition in boreal spruce forests (Økland et al. 1999). In tropical forests, properties of individual trees have proven to affect the distribution of lianas (Nesheim \& Økland 2007), but it remains unknown whether understorey species composition is more effectively predicted by local tree neighborhood or by average stand properties (Berger \& Puettmann 2000, Thomsen et al. 2005, Barbier et al. 2008).

Ecological Field Theory (EFT) is a methodology for studying the interaction between plants of different size (Wu et al. 1985, main features of EFT is that it addresses interactions within a spatial context by determining a domain or size of the influence field. EFT models of tree influence express the effect of tree $(s)$ on a given point $x$ in the space as an exponential function of individual tree properties and the point's distance to neighboring trees. EFT models have been applied to studies of single-tree influence on soil chemical properties, radiation at forestfloor level, seedling growth and understorey vegetation composition (Pukkala et al. 1993, Økland et al. 1999) in boreal forests with one dominant tree species (e.g., Norway spruce, Scots pine). To our knowledge, however, EFT models have not yet been applied Kuuluvainen \& Pukkala 1989). One of the
(1) Centre for Ecology and Economics, Norwegian Institute for Air Research, P.O. Box 100, 2027 Kjeller (Norway); (2) Department of Research and Collections, Natural History Museum, University of Oslo, P.O. Box 1172, Blindern, 0318 Oslo (Norway)

@, Hai-Ying Liu (hyl@nilu.no)

Received: Oct 24, 2011 - Accepted: Jun 30, 2012

Citation: Liu H-Y, Halvorsen R, 2012. Singletree influence on understorey vegetation in five Chinese subtropical forests. iForest 5 : 179-187 [online 2012-08-02] URL:

http://www.sisef.it/iforest/contents? id $=$ ifor $0623-005$

Communicated by: Renzo Motta

to assess the influence of single-tree properties on the composition of the understorey in (sub-) tropical forest (Walker et al. 1989).

Constrained Ordination (CO) is a family of multivariate statistical methods that optimize the fit of abundance data for species in sample plots to one or a set of explanatory (constraining) variable(s), under the assumption that variation in species abundance along the constraining variable(s) gradients is in accordance with a given species response model (ter Braak \& Prentice 1988). The fit of data to an explanatory variable (provided the response model is appropriate) is measured by the eigenvalue of the $\mathrm{CO}$ axis (ter Braak 1986, 1987, Borcard et al. 1992). Eigenvalues corresponding to different constraining variables, measured in the same set of sample plots, may thus be compared (Rydgren 1994, Økland \& Eilertsen 1994, Aude \& Lawesson 1998, Økland 1999). Furthermore, constrained ordination is likely to be suited for finding the combination of singletree influence index parameters that optimizes the fit to species abundance data (Økland et al. 1999).

Every CO method is derived from an ordination method by addition of a multiple regression step that makes the $\mathrm{CO}$ axes linear combinations of explanatory variables, while ordination axes are gradients in species composition per se, not influenced by measured explanatory variables (ter Braak 1986, Økland 1996). The success of ordination methods in extracting the true gradient structure in a data set is, above all, dependent on the appropriateness of the species response model (Økland 1990). In data sets with low $\beta$ diversity (low compositional turnover), species respond more or less linearly to the main gradients, while more species tend to have unimodal species responses in data sets with higher $\beta$-diversity (Økland 1990). Thus, ordination methods based upon a unimodal 


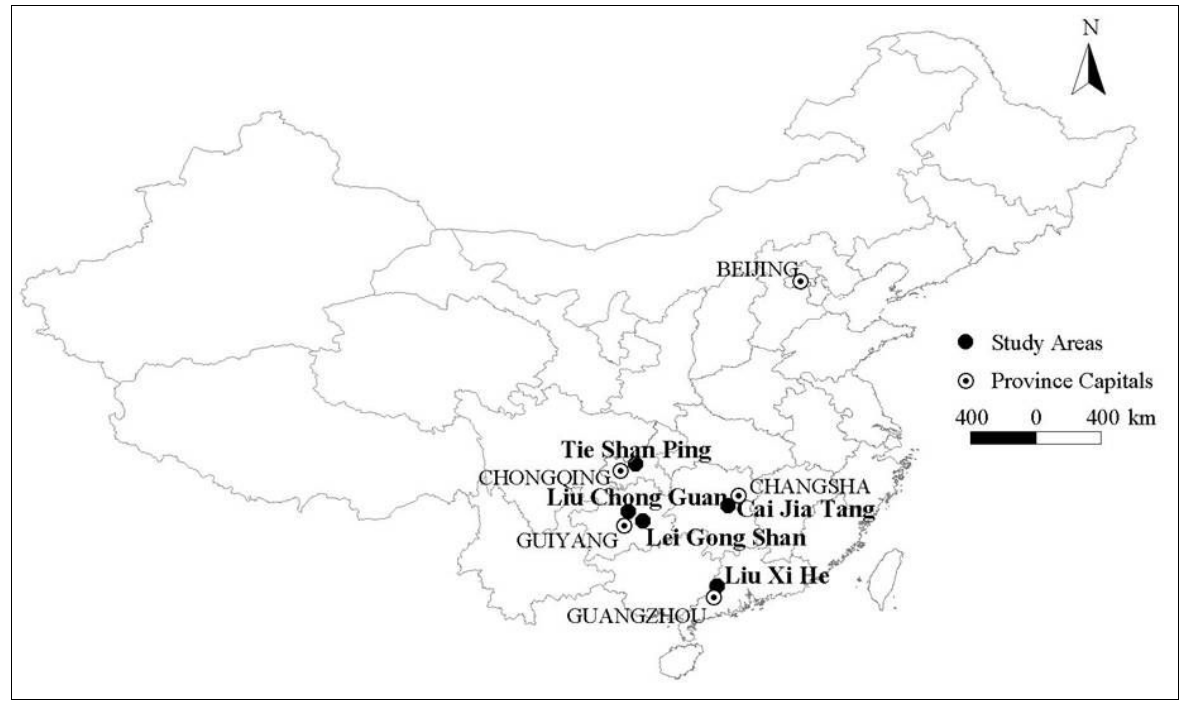

Fig. 1 - Map of China showing the position of the five study areas.

species response model perform relatively better compared to methods based upon a linear model when $\beta$-diversity becomes higher (Økland 1990, ter Braak \& Wiertz 1994). Økland et al. (1999) has tested the influence of response model appropriateness on the reliability of estimates of the variation explained by two $\mathrm{CO}$ methods, Redundancy Analysis (RDA) and Canonical Correspondence Analysis (CCA), concluding that the linear species response model in RDA was more appropriate than the unimodal species response model of CCA in single tree influence on understorey vegetation in a Norwegian boreal spruce forest.

For forests ranging from boreal via temperate (Ozaki \& Ohsawa 1995) and subtropical (Chen et al. 1997, Enoki \& Abe 2004, Zhao et al. 2005, Liu et al. 2008) to tropical (Tuomisto et al. 1995, Svenning 1999), gradients in understorey species composition were shown to be related to forest litter layer depth, topography, soil moisture, soil $\mathrm{pH}$ and soil nutrients, all of which co-vary along a gradient of overstorey tree density (MaltezMouro et al. 2005, Laughlin \& Abella 2007). However, studies in five Chinese subtropical mixed conifer and broadleaf forests (Liu et al. 2008) revealed a distinct relationship between understorey species composition and forest density in only two out of

Tab. 1 - Summary characters of the study sites: number of trees (total and for two functional types) and number of tree species.

\begin{tabular}{lcccc}
\hline \multirow{2}{*}{ Study area } & \multicolumn{3}{c}{ Number of trees (absolute count) } & Number of tree \\
\cline { 2 - 4 } & $\begin{array}{c}\text { All } \\
\text { trees }\end{array}$ & Conifer trees & Broadleaf trees & $\begin{array}{c}\text { Npecies } \\
\end{array}$ \\
\hline Tie Shan Ping (TSP) & 167 & 116 & 51 & 23 \\
Liu Chong Guan (LCG) & 118 & 75 & 43 & 23 \\
Lei Gong Shan (LGS) & 151 & 120 & 31 & 26 \\
Cai Jia Tang (CJT) & 123 & 19 & 104 & 35 \\
Liu Xi He (LXH) & 184 & 1 & 183 & 50 \\
\hline
\end{tabular}

$1736 \mathrm{~mm}$, respectively (1971-2002, data from Chinese Meteorological Administration).

In all study areas parent material is sedimentary rocks such as sandstone and shale, except LXH which was dominated by granites. Soils belong to Haplic Alisol and Acrisol according to the Food and Agriculture Organization of the United Nations (FAO) classification system (Liu et al. 2008).

The study sites had a mixed conifer-broadleaf trees composition. Dominant species in TSP and LCG were Masson pine (Pinus massoniana L.) and Chinese fir (Cunninghamia lanceolata L.); in LGS Armand pine (Pinus armandii F.) and Chinese fir; in CJT Masson pine and sweet gum ( $\mathrm{Li}$ quidambar formosana $\mathrm{H}$.); and in $\mathrm{LXH}$ short-flowered machilus (Machilus breviflora B.) and itea (Itea chinensis H.\&A. Tab. 1). Tree stands in all five study sites were about 40-45 years old. Many of the forests were planted in the $1960 \mathrm{~s}$, after most Chinese forests were logged during the "Great Leap Forward" (1958-1962). At the time this study was carried out, four (TSP, LCG, LGS, and LXH) of the five study areas were protected by law. Three areas (TSP, LCG and LXH) have been exposed to pressure by tourism in recent years. However, there is no evidence of large-scale, human-induced, recent disturbances (except for the impact by "acid rain") in any study area (Liu et al. 2008).

Sampling, recording of trees and understorey vegetation

The five study areas (two south-facing, two north-facing, one east-facing), covering 4 200-10 $800 \mathrm{~m}^{2}$ in Chinese subtropical forests, were selected so as to: (1) span across some of the regional climatic and geographical variation in Chinese subtropical forests; and (2) include most of the variation in the main local environmental gradients (e.g., soil nutrient content, soil moisture, tree density, etc.). The long axis of each study forest ran in the direction of maximum slope.

All the five study areas were irregular, 60 to $90 \mathrm{~m}$ broad and $70-120 \mathrm{~m}$ long. Characteristics of the stands, the details of approach and selection of study areas, placement of plots within each study area were given by Liu et al. (2008).

In each of the five study areas we applied a stratified random sampling design: ten macro plots, each $10 \times 10 \mathrm{~m}$ in size, were established in order to capture the higher possible variation along important ecological gradients (e.g., aspect, nutrient conditions, light supply, topographic conditions, soil moisture, etc.). Five $1-\mathrm{m}^{2}$ vegetation plots were placed at random in each $10 \times 10 \mathrm{~m}$ macro plot, resulting in $501-\mathrm{m}^{2}$ plots in each study area. Each $1-\mathrm{m}^{2}$ plot was divided into 16 subplots, $0.0625 \mathrm{~m}^{2}$ in size. All plots 
Fig. 2 - The meaning of the parameter $a$ in the EFT tree influence model (eqn. 10), explained by the tree influence factors $\varphi$ (eqn. 4).

Axis 1: parameter $a$, axis 2:

factor $\varphi$. Parameter $a$ determines the relative weight to be given to trees of different sizes; with $a=0$, tree size has no effect on $\varphi$, while with $a=1$ the relative importance of trees is proportional to their diameter at breast height. With $0<a<1$, the weight varies within these limits.

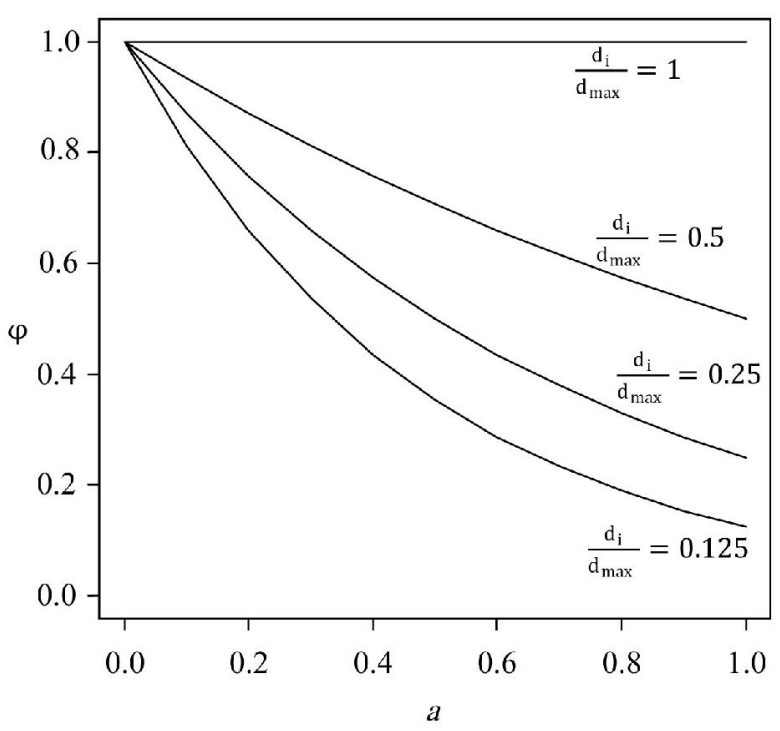

were permanently marked by subterranean aluminum tubes as well as with visible plastic sticks.

Within each macro plot, in the five sample stands, all trees higher than $2 \mathrm{~m}$ (overall 743 trees, of which 331 were conifer, 432 broadleaf - see Tab. 1) were mapped with respect to stem center and crown perimeter. Tree height $(h)$ and diameter at breast height $(d b h)$ were measured. The crown radius $(k)$ was calculated as the mean of crown radil measured in eight cardinal directions.

Presence/absence of all understorey vascular plants and bryophyte species was recorded in each of the $160.0625-\mathrm{m}^{2}$ subplots. Frequency (count of individuals at the subplot) was used as a measure of species abundance (Økland 1988).

\section{Single-tree influence model}

We computed single-tree influence model used by Økland et al. (1999). The model was developed based upon the principles of EFT (Wu et al. 1985) and six assumptions (Kuuluvainen \& Pukkala 1989, Kuuluvainen et al 1993):

(1) The influence of tree $i, I_{\mathrm{i}}$, at a particular point in space depend on: (i) the size of tree $i$ relative to that of the largest tree encountered in the area (a parameter $a$ specifies the exponent given to large $v s$. small trees - see eqn. 4, Fig. 2); and (ii) the distance from the point on the forest floor to the stem center of tree $i$ (a parameter $b$ specifies the exponent given to position close to the stem center relative to positions far away from the stem center - see eqn. 5, Fig. 3; another parameter $c$ specifies the limit for tree influence, measured in crown radius units - see eqn. 6, Fig. 3 ). The influence of tree $i$ is considered to be symmetrically distributed around the stem center.

(2) The influence of tree $i$ on a point on the forest floor at distance $s$ (measured in $\mathrm{dm}$ ) from the stem center can be expressed as a product of two factors (eqn. 1):

$$
I_{i}=\varphi_{i}\left(h_{i} ; a\right) \cdot \psi_{i}\left(s_{i}, k_{i} ; b, c\right)
$$

where $\varphi_{\mathrm{i}}\left(h_{\mathrm{i}} ; a\right)$ - the size factor - weighs trees by their size, e.g., by using the ratio of the height $h$ of the $i$-th tree (measured in $\mathrm{dm}$ ) to the highest tree encountered in the study area (which is arbitrarily given the value of $\varphi=1) ; \psi_{\mathrm{i}}\left(s_{\mathrm{i}}, k ; b, c\right)$ - the distance factor weighs points on forest floor in space by their distance $s$ from the stem of the tree. The parameter $k_{\mathrm{i}}$ denotes the crown radius of tree $i$ (measured in $\mathrm{dm}$ ). By arbitrarily defining $\psi\left(0, k_{\mathrm{i}} ; b, c\right)=1$ for a point situated at the stem center $(s=0), I_{\mathrm{i}}$ takes on values between 0 and 1 . The resulting model has three parameters, $a, b$ and $c$ (Fig. 2, Fig. 3), and expresses tree influence as a function of $h, s$ and $k$.

(3) The size factor $\varphi_{\mathrm{i}}$ can be adequately modeled as a function of the height $h$ of tree $i$ and a parameter $a^{\prime}$, which determines the exponent given to high $v s$. short trees (Fig. 2), as follows (eqn. 2):

$$
\varphi_{i}\left(h_{i} ; a^{\prime}\right)=\left(\frac{h_{i}}{h_{\max }}\right)^{a^{\prime}}
$$

where $h_{\max }$ is the height of the largest tree encountered in the study area. The height of a tree is allometrically related to the tree's diameter $d$ at breast height by the following equation (eqn. 3 ):

$$
h_{i}=r_{0} \cdot d_{i}^{r}
$$

Because $d$ is more easily measured than $h$, Økland et al. (1999) used the following expression for the size factor $\varphi_{\mathrm{i}}$ (eqn. 4):

$$
\varphi_{i}\left(h_{i} ; a\right)=\left(\frac{d_{i}}{d_{\max }}\right)^{a}
$$

where $a$ equals $r a^{\prime}$ and $d_{\max }$ is the maximum diameter recorded for any tree in the study area.

(4) The distance factor $\psi_{\mathrm{i}}$ can be adequately modeled as a function of $s$ and $k$ based upon principles of EFT as follows (eqn. 5):

$$
\psi_{i}\left(s_{i}, k_{i} ; b, c^{\prime \prime}\right)=\exp \left[-c^{\prime \prime} \cdot\left(\frac{s_{i}}{k_{i}}\right)^{b}\right]
$$

The parameter $b$ in eqn. 5 determines the relative exponent given to positions close to the stem center relative to positions further away from the stem (Fig. 3). The parameter $c^{\prime \prime}$ determines the zone of influence by tree $i$. The function $\psi_{\mathrm{i}}$ as given by eqn. 5 takes on positive values for all $s$, but in order to simplify the model, Økland et al. (1999) truncated the its distribution by setting $\psi=0$ for all $s$ that corresponded to $\psi_{\text {i values }}<0.005$. The value of $s$ corresponding to $\psi=0.005$, i.e., the limit for tree influence, was denoted by $c^{\prime}$. The limit for tree influence measured in crown radius units, $c$ (Fig. 3 ), was defined as (eqn. 6):

$$
c=\frac{c^{\prime}}{k} \Leftrightarrow c^{\prime}=c \cdot k
$$

By inserting $\psi=0.005$ and $c \cdot k$ for $s$ in eqn. 5, Økland et al. (1999) obtained the following expression for $c^{\prime \prime}$ (eqn. 7):

$$
\begin{gathered}
\psi_{i}\left(c \cdot k_{i}, k_{i} ; b, c^{\prime \prime}\right)=\exp \left[-c^{\prime \prime} \cdot\left(\frac{c \cdot k_{i}}{k_{i}}\right)^{b}\right]= \\
=0.005 \Leftrightarrow c^{\prime \prime}=-\ln \frac{0.005}{c^{b}}=5.298 \cdot c^{-b}
\end{gathered}
$$

Inserting eqn. 7 into eqn. 5 gave (eqn. 8):

$$
\psi_{i}\left(s_{i}, k_{i} ; b, c\right)=\exp \left[-5.298 \cdot\left(\frac{s_{i}}{c \cdot k_{i}}\right)^{b}\right]
$$

(5) The crown radius $k$ of a tree is allometrically related to the tree's height $h$ and, hence, to the diameter $d$ of the tree. Økland et al. (1999) therefore used the easily obtained information on $d$ in their calculation of $\psi_{\mathrm{i}}$, based upon the general relationship between $k$ and $d$ given by (eqn. 9):

$$
k_{i}=t_{0} \cdot d_{i}^{t}
$$

Insertion of eqn. 9 in eqn. 8 , and eqn. 8 and eqn. 4 in eqn. 1 gave the following expression for $I_{\mathrm{i}}$ (eqn. 10):

$$
\begin{gathered}
I_{i}=\varphi_{i}\left(k_{i} ; a\right) \cdot \psi_{i}\left(s_{i}, k_{i} ; b, c\right)= \\
=\left(\frac{d_{i}}{d_{\max }}\right)^{a} \cdot \exp \left[-5.298 \cdot\left(\frac{s_{i}}{c \cdot t_{0}} \cdot d_{i}^{t}\right)^{b}\right]
\end{gathered}
$$

where $t_{0}$ and $t$ are constants.

(6) The total influence of all $n$ trees adjacent to a point $x, I(x)$, is adequately modeled by the multiplicative model (eqn. 11): 
$I_{i}(x ; a, b, c)=1-\prod_{i=1}^{n}\left[1-I_{i}\left(d_{i}, s_{i}(x) ; a, b, c\right)\right]$

This model, with different values of $a, b$ and $c$ (Fig. 2, Fig. 3), was computed separately by using data on tree size and position relative to the plots in all study areas. Overall, 240 plots were used for vascular plant species, 50 in TSP, LCG, LGS and LXH, and 40 in CJT (excluding 10 plots located in pure bamboo stands). Overall, 212 plots were used for bryophytes species, 40 in TSP (excluding 10 plots devoid of bryophytes), 36 in LCG (excluding 14 plots devoid of bryophytes), 50 in LGS, 40 in CJT (excluding 10 plots located in pure bamboo stands) and 46 (excluding 4 plots devoid of bryophytes) in LXH, respectively.

\section{Statistical analysis}

Before determining the optimal values of the parameters $a, b$ and $c$ of the model, we used parameters $k$ and $d$ to estimate $t_{0}$ and $t$ by standard linear regression (eqn. 12):

$$
\ln \left(k_{i}\right)=\ln \left(t_{0}\right)+t \cdot \ln \left(d_{i}\right)
$$

For all combinations of the two vegetation groups in all five study areas, two species response models, CCA (ter Braak 1986, 1987) and RDA (Rao 1964, ter Braak 1986, 1987), were used to determine the values for parameters $a, b$ and $c$ in the EFT tree influence model (eqn. 10, eqn. 11) that maximized the eigenvalue of a constrained ordination axis constrained by the tree influence index (Økland et al. 1999). RDA assumes that species abundance values are linearly related to the explanatory variables, and CCA assumes unimodal distribution of species abundance values with respect to the explanatory variables. The two vegetation groups (all with 240 and 212 sample plots and subplot frequency data, respectively) used were: (1) vascular plants (330 species), and (2) bryophytes species (110 species).

The "vegan" package developed in R (Oksanen 2010) was used for all multivariate analyzes. For each data set, species with a frequency lower than the median frequency were down-weighted by multiplication by the ratio of the species frequency and the median frequency (Eilertsen et al. 1990). RDA was run after centering of species abundances, otherwise standard options were used.

Initial analyzes showed that the influence of parameters $a$ versus parameters $b$ and $c$ on the variation explained by CCA axis, using modeled tree influence as the only constraining variable, was largely negligible (1-3\%) and lower than the variation explained by RDA axis (1-10\%), and all five vegetation data sets showed relative low $\beta$-diversity (low compositional turnover - Tab. 4). Therefore, as proved in the Norwegian boreal spruce forests (Økland et al. 1999), RDA was more appropriate than CCA in the study of single tree influence on understorey vegetation, hence, we only used RDA model in this study. Furthermore, as observed by Økland et al. (1999) for boreal conifer forests, $a=0.6$ turned out to be close to optimal for all data sets. We therefore used $a=0.6$ in all our analyzes. Optimal values for parameters $b$ and $c$ for each of the 15 data sets (combinations of study area and species group) were found by running series of RDA analyzes, all with the tree influence index $I$ as the only constraining variable, setting $b=0$, $0.5,1.0,1.5, \ldots, 10.0$, and $c=1.0,1.5, \ldots$, 10.0. In order to construct an overall model for all five sites, optimal values of parameters $b$ and $c$ obtained from each best-fitting models for the five study areas have been also compared.

Regardless of the choice of model parameters, only trees closer than approx. 2.5 crown radius units from the mid-point of a sample plot were used for calculation of the index $I$, since the negligible influence played by trees farther away.

Given a set of parameter values, the variation explained by the tree influence index $I$ was expressed as the eigenvalue of the first

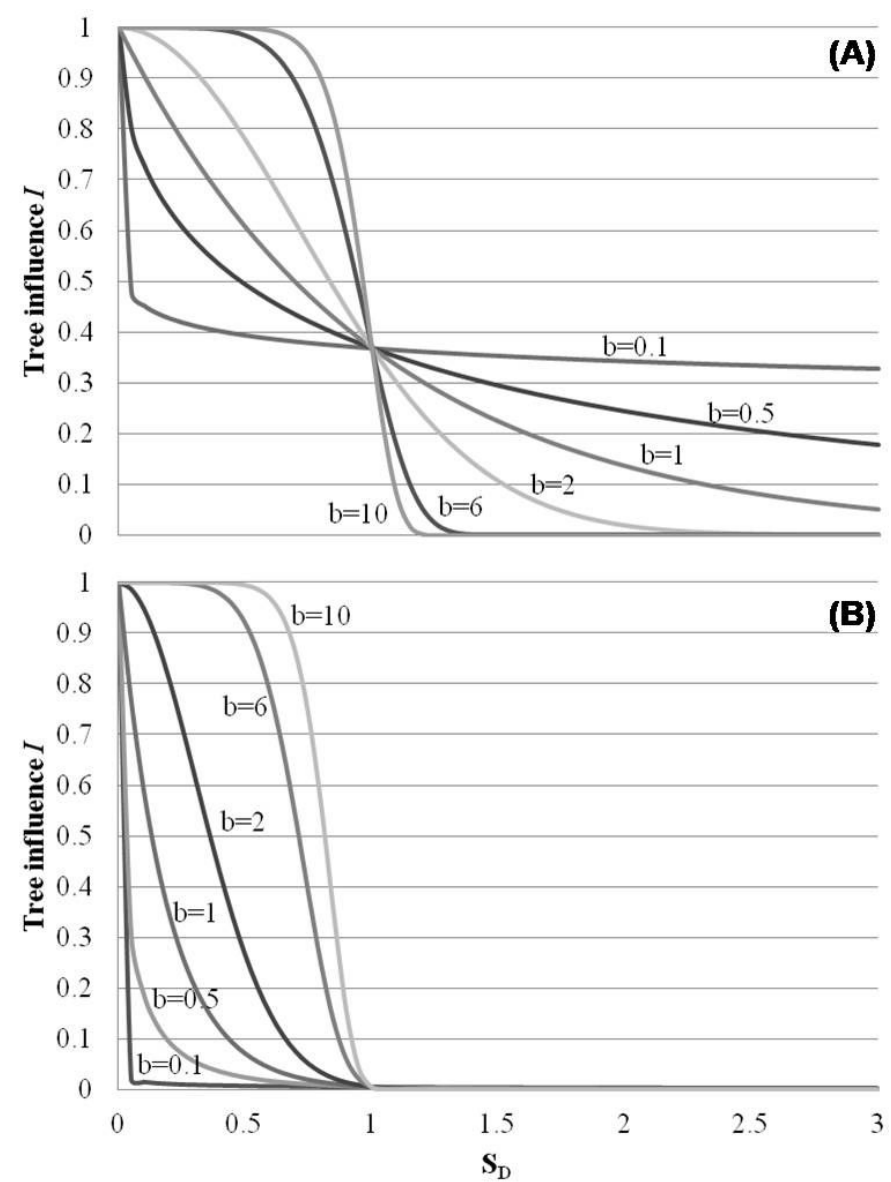

Fig. 3 - Meaning of parameters $b$ and $c$ in the EFT tree influence model (eqn. 10), explained by the tree influence $I$. Horizontal axis: factor $S_{\mathrm{D}}(=s / c k)$; vertical axis 2 : tree influence $I$. For simplicity, $d_{\mathrm{i}}=$ $d_{\max }$. The parameter $b$ can be visualized by replacing the parameter 5.298 with unity $(5.298=>1)$ in the tree influence model (eqn. 10): for $b=1$, the tree influence with increasing dimensionless distance $S_{\mathrm{D}}=s / c k$ from the tree is an exponential decay: $\mathrm{e}^{-S_{\mathrm{D}}}$. For $b<1$ the tree influence decays faster than an exponential for $S_{\mathrm{D}}<1$ and slower than an exponential for $S_{\mathrm{D}}>1$. For $b>1$ the tree influence starts off horizontally with little loss in influence (the derivative of the tree influence is zero at the stem, $S_{\mathrm{D}}=0$ ) it decays slower than an exponential for $S_{\mathrm{D}}<1$ and faster than an exponential for $S_{\mathrm{D}}>1$, and $b=2$ gives a Gaussian decay. This trend is shown for different values of $b$ in (A). Note that for $S_{\mathrm{D}}=1$ all curves have the same value $\mathrm{e}^{-1}$. By raising the functions in (A) to the power 5.298 all the curves that are less than unity everywhere are pushed down, and for $S_{\mathrm{D}}=1$ all the curves have a value equal to $\left(\mathrm{e}^{-1}\right)^{5.298}=\mathrm{e}^{-5.298}=0.005$ as illustrated in (B). In the model $S_{\mathrm{D}}=1$ or $S=c \cdot k$ is defined as the maximal range of tree influence. Consequently, the interpretation of the parameter $c$ is the maximal range of tree influence measured in units of crown radii $k$. For $c=4$, the tree has no influence beyond four times crown radii. 
Tab. 2 - Relationship between tree measurements in all five study areas. All regressions were significant at $p<0.001$. (Int $\left.t_{0}\right)$ : intercept; $(t)$ : regression coefficient (see eqn. 12).

\begin{tabular}{|c|c|c|c|c|c|c|c|}
\hline \multirow{2}{*}{$\begin{array}{l}\text { Study } \\
\text { area }\end{array}$} & \multicolumn{2}{|c|}{$\begin{array}{l}\text { Diameter at breast } \\
\text { height }(d, \mathrm{~cm})\end{array}$} & \multicolumn{2}{|c|}{$\begin{array}{c}\text { Crown radius } \\
(k, \mathbf{d m})\end{array}$} & \multirow{2}{*}{$\begin{array}{l}\text { Parameter's } \\
\text { values }\end{array}$} & \multirow{2}{*}{$\begin{array}{r}\text { Coefficient of } \\
\text { determination }\end{array}$} & \multirow{2}{*}{$\mathbf{n}$} \\
\hline & Average & $\begin{array}{l}\text { Standard } \\
\text { deviation }\end{array}$ & Average & $\begin{array}{l}\text { Standard } \\
\text { deviation }\end{array}$ & & & \\
\hline TSP & 14.45 & 6.9 & 17.78 & 6.65 & $\begin{array}{l}t_{0}=6.062 \\
t=0.396\end{array}$ & $r^{2}=0.309$ & 167 \\
\hline LCG & 18.09 & 9.87 & 20.01 & 7.67 & $\begin{array}{l}t_{0}=6.910 \\
t=0.360\end{array}$ & $r^{2}=0.264$ & 118 \\
\hline LGS & 20.92 & 8.53 & 20.23 & 8.82 & $\begin{array}{l}t_{0}=3.428 \\
t=0.570\end{array}$ & $r^{2}=0.363$ & 152 \\
\hline CJT & 11.3 & 6.59 & 14.15 & 6.85 & $\begin{array}{l}t_{0}=2.494 \\
t=0.705\end{array}$ & $r^{2}=0.487$ & 123 \\
\hline LXH & 12.44 & 7.54 & 18.47 & 10.59 & $\begin{array}{l}t_{0}=2.270 \\
t=0.813\end{array}$ & $r^{2}=0.517$ & 184 \\
\hline
\end{tabular}

Tab. 3 - Number of species per plot and macro plot in each of the five study areas.

\begin{tabular}{lllccc}
\hline \multirow{2}{*}{$\begin{array}{l}\text { Study } \\
\text { area }\end{array}$} & \multirow{2}{*}{ Species group } & \multicolumn{2}{c}{$\begin{array}{c}\text { Number of species } \\
\text { per plot }\end{array}$} & \multicolumn{2}{c}{$\begin{array}{c}\text { Number of species } \\
\text { per macro plot } \\
\text { Range }\end{array}$} \\
\cline { 3 - 6 } & & Mange & Median & $13-23$ & 19.5 \\
\hline TSP & Vascular plants & $2-12$ & 6 & $1-9$ & 5.5 \\
& Bryophyte species & $1-6$ & 3 & $7-20$ & 13 \\
\multirow{2}{*}{ LCG } & Vascular plants & $1-10$ & 5 & $0-12$ & 6 \\
& Bryophyte species & $1-8$ & 3 & $20-32$ & 24.5 \\
LGS & Vascular plants & $7-25$ & 13 & $6-17$ & 12 \\
& Bryophyte species & $1-12$ & 7 & $15-28$ & 21 \\
CJT & Vascular plants & $2-10$ & 6 & $0-4$ & 1 \\
& Bryophyte species & $1-7$ & 4 & $23-50$ & 34 \\
LXH & Vascular plants & $3-23$ & 11 & $2-18$ & 5.5 \\
& Bryophyte species & $1-7$ & 3 & & \\
\hline
\end{tabular}

(and only) constrained ordination axis. Because total inertia (TI, the sum of all unconstrained eigenvalues of the corresponding PCA - Principal Components Analysis - or CA - Correspondence Analysis - ordination) is a univariate variable as a measure of the
1994). After the optimal set of parameters had been found, a distribution-free Monte Carlo simulation test (Legendre \& Legendre 1998) was performed, in which the variation explained by the constraining variable was compared with the variation explained by each of 9999 randomized rearrangements (permutations) of this variable. The test statistics was the partial $F$-statistic, with model and residual sums of squares totaled across species (ter Braak \& Wiertz 1994, Oksanen 2010).

Differences in variation explained and compositional turnover $(\beta$-diversity, gradient lengths in S.D. units) between study areas and species groups were tested for significance using the Kruskal-Wallis test (Sokal \& Rohlf $1995-\alpha<0.01$ ). The strength of relationships between variation explained and gradient lengths was evaluated using the Kendall's non-parametric correlation coefficient $\tau$ (Sokal \& Rohlf 1995).

\section{Results}

The total number of conifer and broadleaf trees varied much among areas. The number of broadleaf trees was relatively high in LXH and CJT, and the opposite was true in TSP and LGS (Tab. 1). The diversity of tree species is relatively high in $\mathrm{LXH}$, and relatively low in TSP and LCG (Tab. 1).

Tests of the regression model in eqn. 12 revealed strongly significant relationships between diameter at breast height $(d)$ and crown radius $(k)$. The regression parameters for the five study areas are presented in Tab. 2 .

The total number of vascular plant and bryophyte species recorded in both the plots and macro plots varied much among areas (Tab. $3)$. In the plots, the number of vascular plant species varied from only 44 in LCG to 125

Tab. 4 - Optimal models for tree influence. Variation is given in inertia units (IU), i.e., the eigenvalue of the RDA axis divided by total inertia (TI). Fr. of TI is the fraction of variation explained by a RDA axis standardized by dividing the eigenvalue of the axis by the total inertia. $p$ values refer to a Monte Carlo test in which the variation explained by the best model was compared with those resulting from 9999 random permutations of the tree influence index based on this model (significance at level $p<0.01$ ). Gradient length is the $\beta$-diversity (in S.D. units) associated with an rhCCA axis (see Methods) obtained by using the tree influence index as the only constraining variable.

\begin{tabular}{|c|c|c|c|c|c|c|c|c|c|c|}
\hline \multirow{2}{*}{$\begin{array}{l}\text { Study } \\
\text { area }\end{array}$} & \multirow{2}{*}{ Species group } & \multirow{2}{*}{$\begin{array}{c}\text { Number } \\
\text { of plots }\end{array}$} & \multicolumn{2}{|c|}{ Parameter values } & \multicolumn{3}{|c|}{ Variation explained } & \multirow{2}{*}{$\begin{array}{l}\text { Length } \\
\text { Fr. of TI }\end{array}$} & \multirow{2}{*}{$p$ value } & \multirow{2}{*}{$\begin{array}{c}\text { Gradient } \\
\text { length }\end{array}$} \\
\hline & & & $\boldsymbol{b}$ & $c$ & Eigenvalue & TI & IU & & & \\
\hline \multirow[t]{3}{*}{ TSP } & All species & 50 & 0 & $\geq 1$ & 1.925 & 61 & 0.032 & 0.043 & 0.004 & 1.363 \\
\hline & Vascular plants & 50 & 10 & 6.8 & 1.421 & 53 & 0.027 & 0.036 & 0.2145 & 2.348 \\
\hline & Bryophyte species & 40 & 0 & $\geq 1$ & 0.602 & 8 & 0.075 & 0.320 & 0.0055 & 0.653 \\
\hline \multirow[t]{3}{*}{ LCG } & All species & 50 & 5.9 & 4.9 & 5.407 & 61 & 0.089 & 0.023 & $<0.0001$ & 2.355 \\
\hline & Vascular plants & 50 & 5.8 & 4 & 2.35 & 44 & 0.053 & 0.028 & $<0.0001$ & 2.61 \\
\hline & Bryophyte species & 36 & 5.8 & $\geq 5.8$ & 3.11 & 17 & 0.183 & 0.098 & $<0.0001$ & 1.378 \\
\hline \multirow[t]{3}{*}{ LGS } & All species & 50 & 4.4 & 3 & 8.366 & 172 & 0.049 & 0.007 & $<0.0001$ & 2.407 \\
\hline & Vascular plants & 50 & 5.1 & 2.9 & 7.55 & 125 & 0.06 & 0.010 & 0.0001 & 2.301 \\
\hline & Bryophyte species & 50 & 2.7 & 1 & 1.192 & 47 & 0.025 & 0.033 & 0.128 & 1.282 \\
\hline \multirow[t]{3}{*}{ CJT } & All species & 40 & 10 & 7.3 & 3.294 & 65 & 0.051 & 0.014 & 0.002 & 1.327 \\
\hline & Vascular plants & 40 & 9.7 & 9.8 & 2.412 & 49 & 0.049 & 0.026 & 0.0046 & 1.425 \\
\hline & Bryophyte species & 40 & 10 & 6.1 & 0.890 & 16 & 0.056 & 0.172 & 0.0308 & 0.739 \\
\hline \multirow[t]{3}{*}{ LXH } & All species & 50 & 10 & 7.2 & 3.965 & 139 & 0.029 & 0.014 & 0.095 & 2.035 \\
\hline & Vascular plants & 50 & 10 & 7.2 & 3.735 & 117 & 0.032 & 0.007 & 0.0352 & 2.408 \\
\hline & Bryophyte species & 46 & 1 & 1 & 0.559 & 22 & 0.025 & 0.066 & 0.3 & 1.393 \\
\hline
\end{tabular}


Fig. 4 - Variation in species composition for the five study areas, each with two species groups, explained by the tree influence index, as a function of parameters $b$ and $c$ in eqn. 10 and eqn. 11. Variation explained is expressed as the ra-

tio of the eigenvalue of the constrained ordination axis obtained by use of the tree influence index as the only constraining variable in an RDA

constrained ordination, divided by the total inertia (see text for further explanation, see also Tab. 4). Axis 1 (horizontal, parameter $c$ ) and axis 2 (vertical, parameter $b$ ).
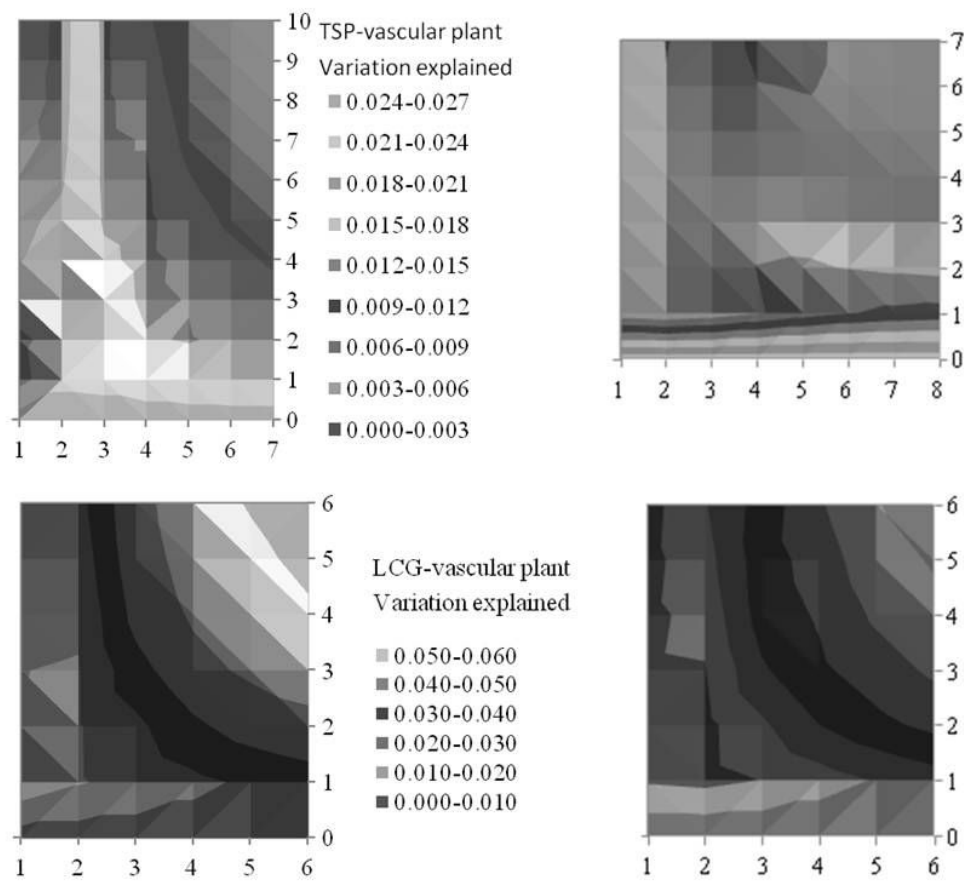

LCG-vascular plant Variation explained $=0.050-0.060$ = $0.040-0.050$ - $0.030-0.040$ = $0.020-0.030$ $=0.010-0.020$ ㅂ. $0.000-0.010$

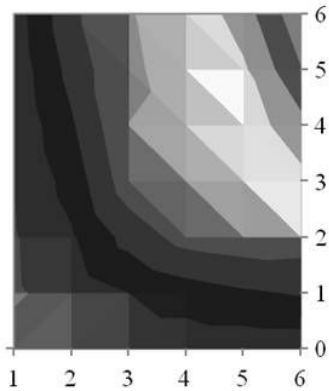

LGS-vascular plant Variation explained

\section{ㅍ. $0.060-0.070$}

$=0.050-0.060$

- $0.040-0.050$

= 0.030-0.040

$=0.020-0.030$

둘.010-0.020

- $0.000-0.010$

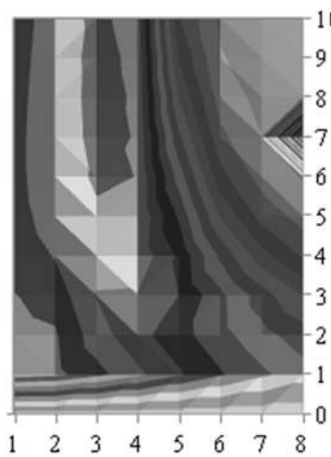

CJT-vascular plant Variation explained $=0.048-0.050$ $0.046-0.048$ $=0.044-0.046$ $=0.044-0.046$
$=0.042-0.044$
$=0.040-0.042$ 0.042-0.044 $=0.040-0.042$ $=0.038-0.040$ $=0.036-0.038$ $=0.034-0.036$ $=0.032-0.034$ - $0.030-0.032$ = $0.028-0.030$ $=0.026-0.028$ $=0.024-0.026$ $=0.022-0.024$ $=0.020-0.022$ $=0.018-0.020$ = $0.016-0.018$

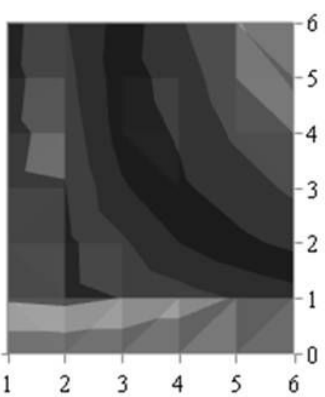

LCG-bryophytes species Variation explained

$=0.180-0.210$

$=0.150-0.180$

$=0.120-0.150$

$=0.090-0.120$

$=0.060-0.090$

$=0.030-0.060$

$=0.000-0.030$
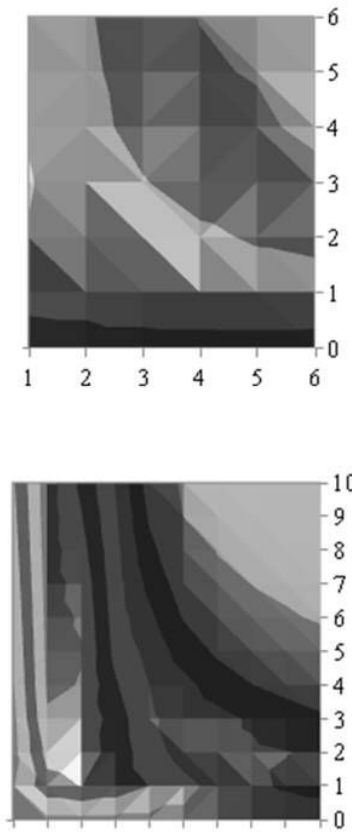

$\begin{array}{llllllllll}1 & 2 & 3 & 4 & 5 & 6 & 7 & 8 & 9 & 10\end{array}$
LGS-bryophytes species Variation explained

$=0.025-0.030$

$=0.020-0.025$

= $0.015-0.020$

$=0.010-0.015$

$=0.005-0.010$

$=0.000-0.005$

CJT-bryophytes species

$=0.055-0.060$

$=0.050-0.055$

$=0.045-0.050$

$=0.040-0.045$

$=0.035-0.040$

= $0.030-0.035$

$=0.025-0.030$

$=0.020-0.025$

- $0.015-0.020$

$=0.010-0.015$

$=0.005-0.010$

$=0.000-0.005$ Variation explained in LGS, and the number of bryophyte species from only 8 in TSP to 47 species in LGS. In the macro plots, the ranking of areas remained the same as that obtained for the plot scale.

In each study area the variation in understorey species abundances accounted for the tree influence index varied systematically as a function of $b$ and $c$. Near-optimal tree influence indexes (i.e., those accounting for the highest percent of the variation) were obtained over a wide range of $b$ or $c$ values for all 10 data sets $(5$ study sites $\times 2$ vegetation groups - Fig. 4, Tab. 4). RDA ordination triplots of plots, species and optimal tree influence index (TI) are reported in Appendix 1.

The maximum "fraction of variation explained" varied considerably among study areas and species groups (Tab. 4 - see also Appendix 1). The maximum explained variation was significantly higher than that associated to a random variable $(p=0.01)$ for nine out of 15 data sets (Tab. 4), without systematic differences among areas (Kruskal-Wallis test: $\chi_{[4]}^{2}=6.47, p=0.167, n=$ 15 ; 5 observations $\times 3$ treatments) or species groups (Kruskal-Wallis test: $\chi_{[2]}^{2}=1.09, p=$ $0.581, n=15 ; 3$ observations $\times 5$ treatments) or vascular plant species $v s$. bryophytes species (Kruskall-Wallis test: $\chi_{[2]}^{2}=2.2, p=$ $0.532, n=10 ; 2$ observations $\times 5$ treatments). The observed variance of vascular plants explained by tree influence was significantly larger than that expected by chance after Monte Carlo tests in LCG, LGS and CJT (Tab. 4, $p<0.01$ ). Analogously, the variance of bryophytes species accounted for tree influence was also significant after Monte Carlo tests in TSP and LCG (Tab. 4, 
$p<0.01)$.

The optimal combination of the parameters $b$ and $c$ differed between study areas and species groups. Relatively high values for $b$ ( $b=5.8$ in LCG, $b=5.1$ in LGS) and low $c$ $(c=4.0$ in LCG, $c=2.9$ in LGS) for vascular plant species were obtained in two (LCG, LGS) out of five areas (Tab. 4). In LCG, the models for vascular plants tend to have same value of $b \quad(b=5.8)$ and relative lower $c$ $(c=4.0)$ for vascular plant species than models for bryophyte species $(b=5.8, c \geq 5.8)$.

In this investigation, study areas and species groups differed in the compositional turnover associated with tree influence best-fitting models, as estimated by rhCCA gradient lengths. Compositional turnover was invariably low for bryophyte species (0.65-1.4 S.D. units in the five areas), while it was $>2.3$ S.D. units for vascular plants in TSP, LCG, LGS and LXH, and 1.3-1.5 S.D units for vascular plants in CJT (Tab. 4) Compositional turnovers were not significantly different among areas (Kruskal-Wallis test: $\chi^{2}{ }_{[4]}=4.5, p=0.343, n=15$ ), while significant differences were found among species groups (Kruskal-Wallis test: $\chi^{2}{ }_{[2]}=7.74$, $p=0.021, n=15)$.

Compositional turnover was not significantly related to the fraction of variation explained by optimal EFT models (Kendall's $\tau$ $=-0.134, p=0.486, n=15$ ).

\section{Discussion}

The five study areas in Chinese subtropical forests analyzed in this study showed strong differences with respect to properties of optimal EFT models for tree influence on the understorey vegetation, as demonstrated by the strong variation in parameters $b$ and $c$. No unified EFT model could be constructed that was valid over the whole range of variation. Furthermore, parameters $(0 \leq b \leq 10$ and $1.0 \leq c \leq 10.0$ - Tab. 4) of optimal models for Chinese subtropical forests strongly contrasted those obtained for boreal spruce forest understorey vegetation in Norway $(b=$ 2.2 and $c=2.5$ ) by Økland et al. (1999). The above results indicate that forest ecosystems differing in dominant canopy trees and situated in different temperature zones are also likely to differ not only in the understorey species composition, but also in the strength and perhaps the mechanism by which the canopy influences the forest-floor environment. For instance, the gap structure in the tree layer (e.g., moving from full cover to openings between trees) has been found to be one of the 2-3 most important vegetation gradient in boreal forests (Økland 1996, Hanley \& Brady 1997). Trees affect vascular plants and bryophytes in different ways: for bryophytes species, high tree influence was found within the crown perimeter, while vascular plants were influenced at larger distances from tree stems (Økland et al. 1999).
However, in (sub-) tropical forests at least in our studied areas, tree-layer density, is found significantly related to vegetation gradient only in two out of five sites (Liu et al. 2008). The mechanism by which the understorey species composition is affected by the structure of the overstorey tree layer is complex (Liu et al. 2008) and remains uncertain (Berger \& Puettmann 2000, Thomsen et al. 2005, Barbier et al. 2008).

In LCG, the difference between vascular plants and bryophytes with respect to parameter combinations that maximized variation explained by the tree influence index, may indicate that trees impact vascular plants and bryophytes in different ways. For instance, conifer dominated forests in acid rain polluted areas on soils poor in nutrients, vascular plants are limited primarily by low availability of water from the soil (Giesler et al. 1998) and by high soil acidity (Liu et al. 2008). Trees influence soil moisture by canopy interception and, perhaps even more strongly, by root uptake of water which may occur over a considerable area (Wilczynski \& Pickett 1993). Higher soil moisture in gaps than below trees (Økland \& Eilertsen 1993, Økland 1996) indicate that soil moisture is correlated with tree influence and tree stand density at both fine and broader scales. Furthermore, trees may influence in a similar way both soil acidity and moisture, since the acidification process directly depends on acid rain pollution (Liu et al. 2008). Indeed, the ordination analysis showed that sites with higher soil $\mathrm{pH}$ also tend to have higher vascular plant species number (Liu et al. 2008).

Tree influence on vascular plant species composition over distances extending 2.94.0 crown radius units away from the stem ( $c=4.0$ in LCG and $c=2.9$ in LGS - Tab. 4) interacts with soil acidity and soil moisture as the most important determinants of vascular plant abundance. Soil texture and chemistry are additional co-varying factors likely to affect vascular plant composition along the gradient from below trees to openings between trees (Økland 1996), as a consequence of the thick layer of loose litter normally occurring under crowns of large conifer trees.

Ordination results showed that bryophytes species are limited primarily by high litter layer depth in LCG (Liu et al. 2008). Higher litter layer depth below conifer trees than below broadleaf trees (Liu et al. 2008) indicates that litter layer depth is correlated with the types of canopy tree. In addition, PCA ordination of environmental variables in LCG showed that litter layer depth is correlated with the topography at both fine and broad scales. This may explain the tree influence on bryophytes species occurring over a certain distance from crown radius.

The mechanisms by which litter layer depth affects bryophytes may be linked to soil moisture and nutrients, since litter plays a major role in forest ecosystems, both as an inherent part of the nutrient and carbon cycling, and regulating microclimatic conditions on the ground (Sayer 2007). However, no significant relationships between litter layer depth and soil moisture/soil nutrients has been found in the studied area (Liu et al. 2008).

In LXH and for bryophytes species in CJT, both dominated by deciduous trees, variance of understorey species composition accounted for by tree influence did not differ from random expectation after Monte Carlo test ( $p>0.01$ - Tab. 4). This may be due to the relatively dense tree coverage (personal field observation) and high forest species richness (Tab. 1) in subtropical broadleaf forests; a situation in which the understorey may be influenced by the overall structure of the forest canopy rather than to neighboring trees alone. Our results suggest that forests dominated by conifer trees (e.g., LCG, LGS) are fundamentally different from broadleaf forests with respect to the mechanism and the extent of tree influence on understorey vegetation, at least in studied subtropical areas.

However, if we consider the biological meaning of the parameters $b$ and $c$ of the optimal EFT models, the relationship between single trees and the understorey may be questioned. As previously mentioned, parameter $b$ is an estimate of the relative distance off the stem at which tree influence reduces most rapidly (Fig. 3); for $b<1$ tree influence rapidly decreases from the stem, while for very large $b$ values $(>>1)$ the maximal reduction takes place further away from the stem (Fig. 3). Similarly, parameter $c$ is an estimate for the distance off the stem (measured in crown radius units) at which tree influence decreases to 0.005 times the value at the stem center (see eqn. 7). For example, with $c=4$, the maximum zone of influence of the largest observed tree (e.g., stem diameter $=54 \mathrm{~cm}(\mathrm{LXH})$, estimated crown radius $=5.35 \mathrm{~m}$ ) is about $21.4 \mathrm{~m} \mathrm{(4} \mathrm{times} \mathrm{the}$ crown radius of approx. $5.35 \mathrm{~m}$ ). Thus, from an ecological point of view, values for parameters $b$ and $c$ outside the range 1-6 hardly make sense (see Fig. 3). In our study the optimal value for $b$ was $>6$ for CJT and 0 for TSP, in which the variation in species abundances explained by the tree influence index was significant (Tab. 4).

This apparent paradox (significant variation in species composition tends to be explained by models whose parameters fall outside the meaningful range) may suggest that, in the studied subtropical forests, trees may influence the understorey vegetation in a collective manner rather than individually, e.g., through properties such as canopy cover (Sterck et al. 1999, Felton et al. 2006), 
throughfall light (Denslow et al. 1998, Francois et al. 2006), soil characteristics (Zhang et al. 2011), etc. This hypothesis also agrees with our results of ordination analyzes of the understorey vegetation of the studied Chinese subtropical forests, where important explanatory factors are litter-layer depth, topography, soil $\mathrm{pH}$ and soil mineral nutrients (Liu et al. 2008, Xiong et al. 2008).

\section{Conclusions and recommendations}

Results from EFT models for tree influence on the understorey vegetation in Chinese subtropical forests may suggest that: (1) single-tree EFT models have limited suitability for subtropical forests; (2) different EFT model parameters, obtained for vascular plants and bryophytes species that maximized the variation explained by the tree influence index, indicates that subtropical trees may impact vascular plants and bryophytes species in the different ways; and (3) subtropical forests comprise many of ecosystem types, which differ with respect not only to variation in species composition along regional climatic and environmental gradients, but also with respect to the way the overstorey influences the understorey vegetation. Subtropical forests, at least those investigated in this study, generally have a closed canopy layer with multi-crown shapes and small canopy gaps, in which light, throughfall precipitation and canopy leaches may be redistributed on ground level in ways that are more or less unrelated to size and location of individual trees. However, this hypothesis should be further investigated. Furthermore, more research on gradient analyzes of forests ground vegetation and its relationships to environmental variables including tree influence index in a range of subtropical forests types are needed.

\section{Acknowledgements}

This study is part of a Sino-Norwegian joint effort for the Integrated Monitoring Program on Acidification of Chinese Terrestrial System (IMPACTS). The IMPACTS project was financially supported by the Norwegian government through NORAD (The Norwegian Agency for Development Co-operation) and Chinese government through MOE (Ministry of Environment). We acknowledge all those who supported the project. We are especially grateful to Quanru Liu, Tonje Økland and Harald Bratli who were involved in fieldwork.

\section{References}

Aude E, Lawesson JE (1998). Vegetation in Danish beech forests: the importance of soil, microclimate and management factors, evaluated by variation partitioning. Plant Ecology 134: 53-65. - doi: 10.1023/A:1009720206762

Barbier S, Gosselin F, Balandier P (2008). Influ- ence of tree species on understory vegetation diversity and mechanisms involved-A critical review for temperate and boreal forests. Forest Ecology and Management 254:1-15. - doi: 10.1016/j.foreco.2007.09.038

Berger AL, Puettmann KJ (2000). Overstory composition and stand structure influence Herbaceous plant diversity in the mixed Aspen forest of Northern Minnesota. American Midland Naturalist 143: 111-125. - doi: 10.1674/0003-0031 (2000)143[0111:OCASSI]2.0.CO;2

Borcard D, Legendre P, Drapeau P (1992). Partialling out the spatial component of ecological variation. Ecology 73: 1045-1055. - doi: $10.2307 / 1940179$

Chen ZS, Hsieh CF, Jiang FY, Hsieh TH, Sun IF (1997). Relations of soil properties to topography and vegetation in a subtropical rain forest in southern Taiwan. Plant Ecology 132: 229-241. - doi: 10.1023/A:1009762704553

Chávez V, Macdonald SE (2010). The influence of canopy patch mosaics on understory plant community composition in boreal mixed wood forest. Forest Ecology and Management 259: 1067-1075. - doi: 10.1016/j.foreco.2009.12.013 Denslow JS, Ellison AM, Sanford RE (1998). Treefall gap size effects on above and belowground processes in a tropical wet forest. Journal of Ecology 86: 597-609. - doi: 10.1046/j.13652745.1998.00295.x

Eilertsen O, Økland RH, Økland T, Pedersen O (1990). Data manipulation and gradient length estimation in DCA ordination. Journal of Vegetation Science 1: 261-270. - doi: 10.2307/ 3235663

Enoki T, Abe A (2004). Saplings distribution in relation to topography and canopy openness in an evergreen broad-leave forest. Plant Ecology 173: 283-291. - doi: 10.1023/B:VEGE.0000029 336.80225.f0

Felton A, Felton AM, Wood J, Lindenmayer DB (2006). Vegetation structure, phenology, and regeneration in the natural and anthropogenic treefall gaps of a reduced-impact logged subtropical Bolivian forest. Forest Ecology and Management 235: 186-193. - doi: 10.1016/j.foreco. 2006. 08.011

Francois LM, Ghislain M, Otto D, Micheels A (2006). Late Miocene vegetation reconstruction with the CARAIB model. Palaeogeography, Palaeoclimatology, Palaeoecology 238: 302-320. doi: 10.1016/j.palaeo.2006.03.034

Giesler R, Högberg M, Högberg P (1998). Soil chemistry and plants in Fennoscandian boreal forest as exemplified by a local gradient. Ecology 79: 119-137. - doi: 10.1890/0012-9658 (1998)079[0119:SCAPIF]2.0.CO;2

Hanley TA, Brady WW (1997). Understorey species composition and production in old-growth western hemlock - Sitka spruce forests of southeastern Alaska. Canadian Journal of Botany 75: 574-580. - doi: 10.1139/b97-064

Greenacre MJ (1984). Theory and applications of correspondence analysis. Academic Press, London, UK.

Kuuluvainen T (1994). Gap disturbance, ground microtopography, and the regeneration dynamics of boreal conifer forests in Finland: a review. Annales Zoologici Fennici 31: 35-51.

Kuuluvainen T, Hokkanen TJ, Järvinen E, Pukkala T (1993). Factors related to seedling growth in a boreal Scots pine stand: a spatial analysis of a vegetation soil system. Canadian Journal of Forest Research 23: 2101-2109. - doi: 10.1139/x93-262

Kuuluvainen T, Pukkala T (1989). Effect of Scots pine seed trees on the density of ground vegetation and tree seedlings. Silva Fennica 23: 159167.

Laughlin DC, Abella SR (2007). Abiotic and biotic factors explain independent gradients of plant community composition in ponderosa pine forests. Ecological Modelling 205: 231-240. doi: 10.1016/j.ecolmodel.2007.02.018

Legendre P, Legendre L (1998). Numerical Ecology. Elsevier Science, Amsterdam, The Netherlands.

Liu HY, Økland T, Økland RH, Gao JX, Liu QR, Eilertsen O, Bratli H (2008). Gradient analyses of forests ground vegetation and its relationships to environmental variables in five subtropical forest areas, S and SW China. Sommerfeltia 32: 1-196. - doi: 10.2478/v10208-011-0012-6

Maltez-Mouro S, Garcia LV, Maranon T, Freitas $\mathrm{H}$ (2005). The combined role of topography and overstorey tree composition in promoting edaphic and floristic variation in a Mediterranean forest. Ecological Research 20: 668-677. - doi: 10.1007/s11284-005-0081-6

Michalet R, Rolland Ch, Joud D, Gafta D, Callaway RM (2002). Associations between canopy and understory species increase along a rain shadow gradient in the Alps: habitat heterogeneity or facilitation? Plant Ecology 165: 145160. - doi: 10.1023/A:1022297624381

Nesheim I, Økland RH (2007). Do vine species in neotropical forests see the forest or the trees? Journal of Vegetation Science 18: 395-404. doi: 10.1111/j.1654-1103.2007.tb02552.x

Økland RH (1990). Vegetation ecology: theory, methods and applications with reference to Fennoscandia. Sommerfeltia Supplement 1: 1-233.

Økland RH (1999). On the variation explained by ordination and constrained ordination axes. Journal of Vegetation Science 10: 131-136. doi: $10.2307 / 3237168$

Økland RH, Eilertsen O (1993). Vegetation-environment relationships of boreal conifer forests in the Solhomfjell area, Gjerstad, S Norway. Sommerfeltia 16: 1-254.

Økland RH, Eilertsen O (1994). Canonical correspondence analysis with variation partitioning: some comments and an application. Journal of Vegetation Science 5: 117-126. - doi: 10.2307/ 3235645

Økland RH, Rydgren K, Økland T (1999). Singletree influence on understorey vegetation in a Norwegian boreal spruce forest. Oikos 87: 488498. - doi: $10.2307 / 3546813$

Økland T (1988). An ecological approach to the investigation of a beech forest in Vestfold, SE Norway. Nordic Journal of Botany 8: 375-407 - 
doi: 10.1111/j.1756-1051.1988.tb00514.x

Økland T (1996). Vegetation-environment relationships of boreal spruce forests in ten monitoring reference areas in Norway. Sommerfeltia 22: $1-349$.

Oksanen J (2010). Multivariate analysis of ecological communities in $\mathrm{R}$ : vegan tutorial. [online] URL: http://cc.oulu.fi/ jarioksa/opetus/metodi/ vegantutor.pdf

Ozaki K, Ohsawa M (1995). Successional change of forest pattern along topographical gradients in warm-temperate mixed forests in Mt Kiyosumi, central Japan. Ecological Research 10: 223-234. - doi: 10.1007/BF02347848

Pukkala T, Kuuluvainen T, Stenberg P (1993). Below-canopy distribution of photosynthetically active radiation and its relation to seedling growth in a boreal Scots pine stand: a simulation approach. Scandinavian Journal of Forest Research 8: 313-325. - doi: 10.1080/0282758930 9382780

Rao CR (1964). The use and interpretation of principal components analysis in applied research. Sankhya Serie A, 26: 329-358.

Rydgren K (1994). Low-alpine vegetation in Gutulia National Park, Engerdal, Hedmark, Norway, and its relation to the environment. Sommerfeltia 21: 1-47.

Sayer EJ (2007). Using experimental manipulation to assess the roles of leaf litter in the functioning of forest ecosystems. Biological Reviews 81:1-31. - doi: 10.1017/S1464793105006846

Sokal RR, Rohlf FJ (1995). Biometry. Freeman, New York, USA.

Sterck FJ, Clark DB, Clark DA, Bongers F (1999). Light fluctuations, crown traits, and response delays for tree saplings in a Costa Rican lowland rain forest. Journal of Tropical Ecology 15: 83-95. - doi: 10.1017/S0266467499000681

Strong WL (2011). Tree canopy effects on understory species abundance in high-latitude Populus tremuloides stands, Yukon, Canada. Community Ecology 12: 89-98. - doi: 10.1556/ComEc. 12.2011.1.11

Svenning J (1999). Microhabitat specialization in a species-rich palm community in Amazonian Ecuador. Journal of Ecology 87: 55-65. - doi: 10.1046/j.1365-2745.1999.00329.x

ter Braak CJF (1986). Canonical correspondence analysis: a new eigenvector technique for multivariate direct gradient analysis. Ecology 67: 1167-1179. - doi: 10.2307/1938672

ter Braak CJF (1987). The analysis of vegetation-environment relationships by canonical correspondence analysis. Vegetatio 69: 69-77. - doi: 10.1007/BF00038688

ter Braak CJF, Prentice IC (1988). A theory of gradient analysis. Advances in Ecological Research18: 271-317. - doi: 10.1016/S0065-2504 (08)60183-X

ter Braak CJF, Wiertz J (1994). On the statistical analysis of vegetation change: a wetland affected by water extraction and soil acidification. Journal of Vegetation Science 5: 361-372. - doi: $10.2307 / 3235860$

Thomsen RP, Svenning J-C, Balslev H (2005). Overstorey control of understorey species composition in a near-natural temperate broadleaved forest in Denmark. Plant Ecology 181: 113-126. - doi: 10.1007/s11258-005-3996-7

Tuomisto H, Ruokolainen K, Kalliola R, Liina A, Danjoy W, Rodriguez Z (1995). Dissecting Amazonian biodiversity. Science 269: 63-66 doi: $10.1126 /$ science 269.5220 .63
Walker J, Sharpe PJH, Penridge LK, Wu H (1989). Ecological field theory: the concept and field tests. Vegetatio 83: 81-95. - doi: 10.1007/ BF00031682

Wilczynski CJ, Pickett STA (1993). Fine root biomass within experimental canopy gaps: evidence for a below-ground gap. Journal of Vegetation Science 4: 571-574. - doi: 10.2307/3236086 Wu H, Sharp PJH, Walker J, Penridge LK (1985). Ecological field theory: a spatial analysis of resource interference among plants. Ecological Modelling 29: 215-243. - doi: 10.1016/03043800(85)90054-7

Xiong YM, Xia HP, Li ZA, Cai XA, Fu SL (2008). Impacts of litter and understory removal on soil properties in a subtropical Acacia mangium plantation in China. Plant Soil 304:179 188. - doi: 10.1007/s11104-007-9536-6

Zhang LW, Mi XC, Shao HB, Ma KP (2011). Strong plant-soil associations in a heterogeneous subtropical broad-leaved forest. Plant and soil. - doi: 10.1007/s11104-011-0839-2

Zhao CM, Chen WL, Tian ZQ, Xie ZQ (2005). Altitudinal pattern of plant species diversity in Shennongjia Mountains, central China. Journal of Integrative Plant Biology 47: 1431-1449. doi: $10.1111 / \mathrm{j} .1744-7909.2005 .00164 . \mathrm{x}$

\section{Supplementary Material}

Appendix 1 - RDA ordination tri-plots of plots, species and optimal tree influence index explaining highest percent of the variation.

Link: Liu_623@supp1001.pdf 